\title{
Analysis of allocation of haplotypes in locuses of prolactin and insulin-like growth factor-I in populations of hens of different breeds
}

\author{
Kulibaba R. ${ }^{1}$, Yurko P. ${ }^{2}$, Liashenko Yu. ${ }^{3}$ \\ $1,2,3$ Institute of animal husbandries of NAAS, \\ 7 Hvardiiska Armiia Str., 3, Kulinichi, Kharkiv area, Kharkiv oblast, 61026, Ukraine \\ e-mail: ${ }^{1,2,3}$ romankx37@gmail.com
}

The purpose. To study frequency of allocation of haplotypes in locuses of prolactin and insulin-like growth factor-I in populations of hens of breeds Plimutrok bilyi (line G-2), Borkivska barvysta (line A), Poltavska hlynysta (line 14) and Rod-island chervonyi (line 38). Methods. PCR, PCR-RLFP. Results. Frequencies of haplotypes in locuses of prolactin and insulin-like growth factor-I in the tested populations of hens are specified. Conclusions. For egg hens it is characteristic predominance of frequency of haplotype IC by locus of prolactin, while for breeds of combined direction of productivity - of haplotype DT. By locus of insulin-like growth factor-I for populations of hens of breeds Plimutrok bilyi and Rod-island chervonyi it is characteristic predominance of frequency of haplotype $\mathrm{C}_{2} \mathrm{~A}$, for all other lines - of haplotype $\mathrm{C}_{2} \mathrm{C}$.

Key words: polymorphy, population, disbalance on cohesion, allele, hens.

The most effective products production is the main scope of modern industrial poultry farming, for this purpose various scientific approaches are used. In poultry selection, one of the most effective approaches is marker-associated selection (MAS, marker-assisted selection) [1]. It was precisely with the use of MAS, as well as even more advanced genomic selection methodology, the leading selection centers of the world received chicken lines, which are characterized by maximum output (egg and meat) [2]. Along with the commercial lines of hens, considerable work is done in the direction of studying the genetic structure as the necessary foundation for the next breeding work, gene pool (local) breeds of chicken in different countries and regions [3-5]. The study of the basic genetic and population parameters of various breeds and chicken lines in a set of molecular genetic markers allows us to estimate the level of genetic variability (allele diversity) up to individual genes, which allows the obtaining of experimental lines with given genotypes in a set of loci. In this regard, it's expedient to study the adhesion of various mutations (polymorphisms) within a single locus, which determines the high probability of a consistent inheritance of genetic variations. For analysis, estimating the unbalance for coupling method is used. The disequilibrium between two polymorphic sites of one locus is expressed in a deviation from the random distribution of the probability of their occurrence [6]. In the case of grip between variable regions of the genome (locus) it is possible to consider them as one functional (linked) element of inheritance. The analysis of imbalance in the grip of various variational sites of the loci, each of which correlates with increased productive qualities of bird, allows individuals to be identified with the most productive haplotypes and, in the future, to receive chicken experimental lines in complexes of the desired haplotypes. In this context, it's relevant to study the imbalance in grip in functional genes, the functioning of which directly is associated with the manifestation of economically useful signs of chickens in different areas of productivity. Such promising targets include prolactin genes and insulin-like growth factor-I.

Scope. Haplotypes frequencies distribution study in the loci of prolactin and insulin-like growth factor-I in the chickens populations of Plymouth rock white (line G-2), Birkivska Barvista (line A), Poltava clay (line 14), and Rhode-Island red (line 38). 
Materials and methods. The research was carried out in the laboratory of poultry diseases prophylaxis and molecular diagnostics of the State Research Station of Poultry Industry of NAAS and in the laboratory of molecular genetic and physiological and biochemical studies in livestock of Institute of Animal Science NAAS.

For research purposes, poultry of Ukrainian breeding was used - egg-lying production line, line A, Birkivska Barvista breed; egg-meat production line - line 14 of Poltava clay breed and the line 38 of Rhode Island red breed; meat-egg production line - line G-2 of Plymouth rock white breed. Chickens kept in laboratory vivarium. Bird blood was used as a source of DNA. DNA isolation, amplification and restriction were performed according to the methods described in our previous work. The frequencies of alleles and genotypes were calculated using standard methods [8].

Haplotypes frequencies were determined by EM algorithm using $\mathrm{EH}+$ program [9]. Calculations of coupling deviation standardized degree from the equilibrium state were performed using the 2LD program [10].

Results. The use of classical PCR and restriction analysis allowed to study chicken populations genetic structure peculiarities of different breeds of Ukrainian breeding by the PRL and IGF-I locus. Taking into account the received data on chicken experimental populations genetic structure of different breeds of Ukrainian breeding, a comparative analysis of prolactin haplotypes frequencies distribution for both polymorphic sites was carried out. Table 1 shows data on the structure and frequency of occurrence in chicken experimental populations of different haplotypes types by the prolactin locus.

Table1. Haplotypes frequencies distribution according to the prolactin loci in the chicken populations of different breeds of Ukrainian selection

\begin{tabular}{|c|c|c|c|c|c|c|}
\hline \multirow{2}{*}{ Haplotype } & \multicolumn{2}{|c|}{ Polymorphism } & \multicolumn{4}{c|}{ Chicken breed } \\
\cline { 2 - 7 } & Indel & C-2402T & $\begin{array}{c}\text { White } \\
\text { Plymouth rock }\end{array}$ & $\begin{array}{c}\text { Birkivska } \\
\text { Barvista }\end{array}$ & Poltava clay & $\begin{array}{c}\text { Rhode Island } \\
\text { red }\end{array}$ \\
\hline 1 & I & C & 0,01 & 0,82 & - & 0,06 \\
\hline 2 & I & T & 0,12 & 0,00 & - & 0,00 \\
\hline 3 & D & C & 0,15 & 0,00 & - & 0,08 \\
\hline 4 & D & T & 0,72 & 0,18 & - & 0,86 \\
\hline
\end{tabular}

According to the results of the conducted research, it was found that full complete LD was observed in the case of egg chickens of Birkivska Barvista breed and egg-meat breed - Rod-Island red (in both cases, the value of the standardized degree of non-equilibrium $D$ 'was 1). In the population of egg-lying chickens, individuals number with haplotype IC (0.82) is significantly higher. At the same time, Rod-Island red breed population is dominated by individuals with a haplotype DT (0.86). In turn, the G-2 line of meat-and-egg-lying chickens is also dominated by individuals with a DT haplotype $(0.72)$, however, the value of $D$ 'in this population was 0.72 ; which significantly exceeds the threshold of significance at $50 \%$. The fact of deviation from the state of genetic equilibrium indicates that the ratio of the alleles that form the haplotype isn't random and isn't determined by a simple correlation of corresponding allelic variants frequencies of the individual loci. At the same time, for haplotypes frequencies distribution analysis for Poltava clay chickens it isn't possible due to monomorphism in one of the mutations (24 Indel). Advantage of individuals number with haplotype IC in the egg production chickens population is confirmed by the data of other authors about the association of the same name alleles with increased hens productive qualities of different breeds. Selection conducted by classical selection methods in the direction of egg-lying indexes increase, has led to the saturation of the experimental population with the desired alleles I and $\mathrm{C}$, which form the haplotype, which influenced the observed pattern in the distribution of frequencies. However, the possibility of masking the undesirable haplotype (in relation to egg productivity) in a heterozygous state, which, in turn, is determined by the codominant imitation type, didn't allow the elimination of individuals with an unproductive haplotype from the population. In the case of egg-lying-meat chickens (line 38), there is a tendency to prevail in the number of individuals with the haplotype DT, which is also probably the indirect result of the breeding work being carried out and the overall "leveling" of the line, which is confirmed by the lowest among the studied populations by values of heterozygosity and effective number of alleles. It should be noted that the advantage of the frequency of the haplotype DT may also be the result of breed specificity, 
which may go against the direction of breeding work. Marker specificity probability (that is the manifestation of an associative relation with any sign in one breed of hens isn't necessarily extrapolated to other breeds) is also important. In any case, the question of the relationship between the studied allelic variants in the prolactin gene and the performance indicators of different lines poultry is relevant and will be investigated in our further work.

Due to obtained data, haplotypes frequencies distribution is going to be analyzed by the locus of the insulinlike growth factor-I for both polymorphic sites in the experimental chicken populations.

Table 2 summarizes the structure and frequency of haplotypes different types occurrence in the IGF-I locus in the chicken lines.

Table 2. Haplotypes frequencies distribution by locus of insulin-like growth factor-I in experimental chicken populations

\begin{tabular}{|c|c|c|c|c|c|c|}
\hline \multirow{2}{*}{ Haplotype } & \multicolumn{2}{|c|}{ Polymorphism } & \multicolumn{4}{c|}{ Chicken breed } \\
\cline { 2 - 7 } & Pstl & Hinfl & $\begin{array}{c}\text { White } \\
\text { Plymouth rock }\end{array}$ & $\begin{array}{c}\text { Birkivska } \\
\text { Barvista }\end{array}$ & Poltava clay & $\begin{array}{c}\text { Rhode Island } \\
\text { red }\end{array}$ \\
\hline 1 & $\mathrm{C}_{1}$ & $\mathrm{~A}$ & 0,14 & 0,01 & 0,03 & 0,06 \\
\hline 2 & $\mathrm{C}_{1}$ & $\mathrm{C}$ & 0,05 & 0,26 & 0,33 & 0,29 \\
\hline 3 & $\mathrm{C}_{2}$ & $\mathrm{~A}$ & 0,54 & 0,26 & 0,26 & 0,36 \\
\hline 4 & $\mathrm{C}_{2}$ & $\mathrm{C}$ & 0,27 & 0,47 & 0,38 & 0,29 \\
\hline
\end{tabular}

Haplotypes frequencies distribution study in each of the experimental lines, with the exception of Plymouth rock white breed, makes it possible to conclude that the equilibrium state is disturbed, that is, in each line of chickens haplotypes frequency isn't determined by the values of corresponding alleles frequencies. The value of the normalized degree of deviation from the equilibrium state $D^{\prime}$ varied from 0.56 to 0.89 ; which exceeds the significance threshold value of $50 \%$. However, when comparing the frequency distribution of haplotypes, some regularities can be seen, which, as already mentioned above, completely correlate with allele frequencies distribution values in the corresponding lines of chickens. Thus, in Rhode-Island red population frequency haplotypes $\mathrm{C}_{1} \mathrm{C}$ and $\mathrm{C}_{2} \mathrm{C}$ are as close as possible to each other in a value that isn't observed in other lines of chickens. For this population, as well as for meat-and-egg-lying chickens, the characteristic predominance of the haplotype $\mathrm{C}_{2} \mathrm{~A}$ is characteristic, while for all others it's the haplotype $\mathrm{C}_{2} \mathrm{C}$. At the same time, the value of the standardized deviation from the state of equilibrium in the line G-2 is minimal and doesn't reach the threshold of significance $\left(D^{\prime}=0.23\right)$. Birkivska Barvista breed egg-lying chicken population is characterized by the maximum value of the standardized degree of deviation from the equilibrium state (0.89), while the Poltava chickens occupy an intermediate position $\left(D^{\prime}=0.70\right)$.

Such a distribution is likely to be interpreted as a direction of poultry productivity. Thus, according to literary sources, allele A (Hinfl-polymorphism of the locus of IGF-I), is associated with increased poultry meat quality, in particular, with live weight indicators [11]. This is reflected in the genetic structure of chicken meat breeds, which are characterized by a pronounced advantage of the allele A frequency, up to the complete absence of homozygous individuals in the population with the genotype CC. In turn, chicken egg-lying breeds are specific, in the advantage of $\mathrm{C}$ allele frequency value. This is all reflected in the distribution pattern of the allelic frequencies of IGF-I for each of the polymorphisms. Also, for meat and egg poultry, in comparison with other experimental lines, the increased frequency of the haplotype $\mathrm{C}_{1} \mathrm{~A}$ is characteristic. In any case, the specificity of the genetic structure of the lines of hens in different areas of productivity provides the prerequisites for further breeding work to maximize poultry productive potential realization. 


\section{Conclusions}

Haplotypes frequencies in prolactin loci and insulin-like growth factor-I in chicken populations of Plymouth rock white, Birkivska Barvista, Poltava clay and Rhode Island red are determined. As a result of research it has been established that egg-lying is characterized by a predominance of the haplotype IC frequency in the prolactin locus, while for the breeds of the combined production (meat-egg-lying and egg-lying-meat) breeds - the haplotype DT. The expressed disequilibrium inhibition in the locus of prolactin for egg chicken breeds is Birkivska Barvista $\left(D^{\prime}=1\right)$. The incidence of haplotype IC in this population was 0.82 . Significant deviation from the equilibrium in the locus of prolactin for the population of the hens of the breed of genus Island ( $\left.D^{\prime}=1\right)$ is shown. Frequency of the haplotype DT was 0.86 . In the locus of the insulin-like growth factor-I, the deviation from the state of equilibrium in the distribution of haplotypes is shown for the chickens populations of Birkivska Barvista breed $\left(D^{\prime}=0.89\right)$, Poltava clay $\left(D^{\prime}=0.56\right)$ and Rhode Island red $\left(D^{\prime}=0.70\right)$. In Plymouth rock chicken population, the deviation from the equilibrium state in the distribution of haplotypes by the IGF-I locus wasn't detected $\left(D^{\prime}=0.23\right)$. For chicken populations of Plymouth rock White and Rhode Island Red breeds are characteristic overriding factor of the haplotype $C_{2} A$, while for all others it's the haplotype $C_{2} C$.

\section{Bibliography}

1. Fulton J.E. (2012). Genomic selection for poultry breeding. Animal frontiers. Vol. 2, № 1. P. 30-36.

2. Wolc A. (2014). Understanding genomic selection in poultry breeding. World poultry science journal. Vol. 70. P. 309-314.

3. Moe H.H., Shimogiri T., Kawabe K. et al. (2009). Genotypic frequency in Asian native chicken populations and gene expression using insulin-like growth factor 1 (IGF1) gene promoter polymorphism. J. Poult. Sci. Vol. 46. P. 1-5.

4. Khadem A., Hafezian H., Rahimi-Mianji G. (2010). Association of single nucleotide polymorphisms in IGF-I, IGF-II and IGFBP-II with production traits in breeder hens of Mazandaran native fowls breeding station. African Journal of Biotechnology. V. 9 (6). P. 805-810.

5. Bagheri Sarvestani A.S., Niazi A., Zamiri M.J. et al. (2013). Polymorphisms of prolactin gene in a native chicken population and its association with egg production. Iranian journal of veterinary research. Vol. 14 (2).

P. 113-119.

6. Slatkin M. (2008). Linkage disequilibrium - understanding the evolutionary past and mapping the medical future. Nature Reviews Genetic. Vol. 9. P. 477-485.

7. Moniruzzaman M. Khatun R., Mintoo A.A. (2014). Application of marker assisted selection for livestock improvement in Bangladesh. The Bangladesh veterinarian. Vol. 31 (1). P. 1-11.

8. Merkurieva E.K. (1977). Geneticheskie osnovi seleksii v skotovodstve [Selection genetic basis in cattle breeding]. Moscow: Kolos [in Russian].

9. Zhao J.H., Curtis D., Sham P.C. (2000). Model-free analysis and permutation tests for allelic associations. Hum Hered. Vol. 50. P. 133-139.

10. Zapata C. Carollo C., Rodriguez S. (2001). Sampling variance and distribution of the D measure of overall gametic disequilibrium between multiallelic loci. Ann Hum Genet. Vol. 65. P. 395-406.

12. Kadlec J., Hosnedlova B., Rehout V. et al. (2011). Insulin-like growth factor-I gene polymorphism and its association with growth and slaughter characteristics in broiler chickens. Journal of Agrobiology. Vol. 28 (2). P. 157-163. 